\title{
CONTROLLING OF Pseudomonas cichorii AND Dickeya dadantii (Erwinia chrysanthemi) BY ELECTROSPUN NANOFIBERS OF NYLON-6/CHITOSAN BLENDS
}

\author{
ABDEL-MEGEED A. ${ }^{1,2^{*}}$, SADIK M.W. ${ }^{3}$, EIFAN S.A. ${ }^{2}$ AND EL-NEWEHY M.H.4,5 \\ ${ }_{1}^{1}$ Department of Plant Protection, Faculty of Agriculture (Saba Basha), Alexandria University, Alexandria 21531, Egypt. \\ 2Department of Botany and Microbiology, College of Science, King Saud University, P.O. Box: 2455 Riyadh 11451, Saudi Arabia. \\ 3Department of Microbiology, Faculty of Agriculture, Cairo University, Giza 12613, Egypt. \\ 4Department of Chemistry, College of Science, King Saud University, P.O. Box 2455, Riyadh 11451, Saudi Arabia. \\ ${ }^{5}$ Department of Chemistry, Faculty of Science, Tanta University, Tanta 31527, Egypt. \\ *Corresponding Author: Email- aamahmoud@ksu.edu.sa
}

Received: August 20, 2013; Accepted: December 19, 2013

\begin{abstract}
This is the first report to use electrospun nanofibers which could be of considerable interest to the development of new antibacterial compounds against certain species of bacteria affect plants in different ways as bacterial leaf spot (bacterial midrib rot), Pseudomonas cichorii and bacterial blight Dickeya dadantii (Erwinia chrysanthemi). Electrospun nylon-6/chitosan (nylon-6/Ch) nanofibers were obtained from formic acid as a single solvent. Surface modification of electrospun nylon-6/chitosan nanofibers was observed by soaking the mat in aqueous solution of glycidyltrimethylammonium chloride (GTMAC) at room temperature overnight to give nylon-6/N-[(2-hydroxy-3-trimethylammonium) propyl] chitosan chloride (nylon-6/HTCC). The morphological, structural and thermal properties of the nylon-6/chitosan nanofibers were studied by field-emission scanning electron microscopy (FE-SEM), X-ray diffraction (XRD), Fourier transform-infrared (FT-IR) spectroscopy, and thermogravimetric analysis (TGA). Biological screening demonstrated that Nylon-6/HTCC mat exhibited high potential antibacterial activity against Pseudomonas cichorii and Dickeya dadantii (Erwinia chrysanthemi) on protein profile. Pseudomonas cichorii and Dickeya dadantii (Erwinia chrysanthemi) examined using SEM were totally deformed and exhibited severe destruction
\end{abstract}

Keywords- Chitosan, nylon-6, glycidyltrimethyl ammonium chloride, Pseudomonas cichorii, Dickeya dadantii (Erwinia chrysanthemi)

Citation: Abdel-Megeed A., et al. (2013) Controlling of Pseudomonas cichorii and Dickeya dadantii (Erwinia chrysanthemi) by Electrospun Nanofibers of Nylon-6/chitosan Blends. International Journal of Biotechnology Applications, ISSN: 0975-2943 \& E-ISSN: 0975-9123, Volume 5, Issue 1, pp.-155-162.

Copyright: Copyright@2013 Abdel-Megeed A., et al. This is an open-access article distributed under the terms of the Creative Commons Attribution License, which permits unrestricted use, distribution and reproduction in any medium, provided the original author and source are credited.

\section{Introduction}

Bacterial pathogens employ diverse strategies to infect their host plants. Losses due to postharvest disease may occur at any time during postharvest handling, from harvest to consumption. When estimating postharvest disease losses, it is important to consider reductions in fruit quantity and quality, as some diseases may not render produce unsalable yet still reduce product value [1]. For example, blemished fruit may not be sold as fresh fruit but may still be suitable for processing, in which case, it brings a lower price. It is also important to take into account costs such as harvesting, packaging and transport when determining the value of produce lost as a result of postharvest wastage [2]. Aside from direct economic considerations, diseased produce poses a potential health risk. The bacteria that cause postharvest diseases of vegetables and fruits belong to five of the six genera of bacteria that cause plant diseases. Among them, members of the genera Pseudomonas and Erwinia, are responsible for the necrotic lesions on leaves, stems, and fruits, and internal discolorations and decay. The Gram-negative bacterium Dickeya dadantii (Erwinia chrysanthemi) is a phytopathogenic bacterium causing soft rot diseases on many crops. E. chry- santhemi has a world-wide distribution. Any kind of strain may occur in temperate countries, where outdoor and glasshouse plants are produced. E. chrysanthemi has also been naturally found to attack many cops as Allium fistulosum, Brassica chinensis, Capsicum, cardamoms, carrots, celery, chicory, Colocasia esculenta, Poaceae such as Brachiaria mutica, B. ruziziensis, Panicum maximum and Pennisetum purpureum, Hyacinthus sp., Leucanthemum maximum, lucerne, onions, pineapples, radishes, rice has been erroneously mentioned as a host [3]. The disease causes destruction of many flower and ornamental crops, particularly carnation and chrysanthemum in rooting beds. Losses are also recorded on different glasshouse ornamentals (Saintpaulia ionantha, Kalanchoe), as well as in potato and Dahlia tuber production. On potatoes, it causes soft rot and blackleg like E. carotovora [4], but the symptoms tend to be expressed at higher temperatures. Seed potato certification schemes producing material for warmer countries should take account of $E$. chrysanthemi [5]. The banana pseudostem rot is rather destructive.

Pseudomonas cichorii is a Gram-negative soil bacterium that is pathogenic to plants. It has a wide host range, and have an im- 
portant economical impact on lettuce, celery and chrysanthemum crops [6]. However, knowledge about the epidemiology and pathogenicity mechanisms of this pathogen is very limited. This seriously hinders the management of diseases of crops and agriculture products [7]. Considering the deleterious effects of synthetic pesticides on life supporting system, there is an urgent need for alternative biological agents for the management of pathogenic microorganisms.

Chitosan has a number of commercial and possible biomedical uses. It can be used in agriculture as a seed treatment and biopesticide, helping plants to fight off bacterial infections [8]. In agriculture, chitosan is used primarily as a natural seed treatment and plant growth enhancer, and as an ecologically friendly biopesticide substance that boosts the innate ability of plants to defend themselves against bacterial infections [9]. The natural biocontrol active ingredients, chitin/chitosan, are found in the shells of crustaceans, such as lobsters, crabs, and shrimp, and many other organisms, including insects and bacteria. It is one of the most abundant biodegradable materials in the world. Chitosan is a polysaccharide composed of $D$ glucosamine residues that are structurally linked similarly to various glycosaminoglycans (GAG) present in the extracellular matrix (ECM) $[10,11]$. As a natural polymer, chitosan possess biodegradable, biocompatible, antimicrobial activity, non-toxicity and versatile chemical and physical properties $[9,12]$.

Nanotechnology is one of the frontier technologies whose deliverables are anticipated to shape the future owing to these properties $[13,14]$. Chitosan in the nanofiber mat form has wide applications in pharmaceutical, medical applications, paper production, wastewater treatment, biotechnology, cosmetics, food processing and agriculture $[15,16]$. On the other hand, nylon- 6 is a biodegradable, biocompatible and synthetic polymeric material which has good mechanical and physical properties $[17,18]$.

In the last few years, polymer nanofibers have received much attention due to their small diameter which mimic the topology of extra cellular matrix present in human body and hence are used as scaffolds in tissue engineering [19]. Among the processes used to prepare nanofibers, electrospinning is regarded as a simple and versatile method to generate nano- to submicrometer fibrous structures [20]. Application of electrospinning to biologically significant polymers has increased since the electrospun membranes were identified as a candidate for tissue engineering constructs [16,21,22]. Electrospun nanofibers have become promising materials for many biomedical applications such as wound dressing [10] drug delivery, scaffold for tissue engineering [16,23,24].

In our work, we take the advantage from both chitosan and nylon-6 by blending them into composite nanofibrous scaffolds for antibacterial applications by introduction of quaternary ammonium salts. Quaternary ammonium compounds (QACs) are some of the most commonly used antimicrobials. Common characteristics among QACs are that they possess both a positive charge and a hydrophobic segment [25].

In this work, we report on the preparation of nylon-6/chitosan nanofibers as a candidate for antibacterial agents. We were able to synthesis nylon-6/chitosan composite nanofibers by blending of chitosan $(8 \%)$ with our Nanospider setup. The morphology of the resulting nanofibers before and after surface modification was analyzed by field-emission scanning electron microscopy (FE-SEM). Then, the structural and thermal properties of electrospun nylon-6/ chitosan nanofibers was demonstrated using X-ray diffraction
$(\mathrm{XRD})$, Fourier transform infrared spectroscopy (FT-IR), and thermogravimetric analysis (TGA). The antibacterial activity of this new finding was demonstrated against Pseudomonas cichorii and Dickeya dadantii (Erwinia chrysanthemi) the main causative of several vegetable and cash crops diseases.

\section{Materials and Methods \\ Materials and Characterization}

Nylon-6 (Ultramid ${ }^{\circledR}$ B24 N 03) was purchased from BASF. Chitosan, low molecular weight, was purchased from Aldrich. Glycidyltrimethylammonium chloride (GTMAC) (technical, $\geq 90 \%$ ) was purchased from Fluka. Formic acid was purchased from Fluka. All materials and solvents were used as received without further purification.

Electrospinning Setup: Electrospinning was carried out using Nanospider laboratory machine NS LAB 500 S from Elmarco s.r.o.

Field-emission Scanning Electron Microscope (FE-SEM): The morphology of electrospun nanofiber was observed using fieldemission scanning electron microscopy (FE-SEM, Hitachi S-7400, Japan). The morphology of the species cells was examined by SEM (S-4100, Hitachi, Japan).

X-Ray Diffraction (XRD): Structural characterization was carried out by X-ray diffraction (XRD, Rigaku, Japan) operated with Cu-Ka radiation $(=1.540 \AA)$.

FT-IR Spectroscopy: Fourier-transform infrared (FT-IR) spectra were recorded to study the encapsulation of the drug into electrospun nanofiber using TENSOR 27, Bruker.

Thermogravimetric Analysis (TGA): Thermal properties of electrospun nanofibers were examined through using thermogravimetric analysis (TGA) which was carried on TA-Q500 System of TA. Samples of $5-10 \mathrm{mg}$ were heated in the temperature range $30-800^{\circ} \mathrm{C}$ at a scanning rate of $10^{\circ} \mathrm{C} \cdot \mathrm{min}^{-1}$ under nitrogen atmosphere.

\section{Preparation of the Spinning Solutions}

Nylon-6/chitosan nanofibrous mat was fabricated using electrospinning process in which, nylon- 6 was dissolved in formic acid at 60 $70^{\circ} \mathrm{C}$ with gentle stirring in order to prepare $12 \%(\mathrm{w} / \mathrm{v})$ homogeneous solution. Chitosan with concentration of $8 \%(\mathrm{w} / \mathrm{w})$ was mixed with the nylon- 6 solution with gentle stirring till complete dissolution. The prepared solution was then used for electrospinning at room temperature.

\section{Electrospinning of Nylon-6/Chitosan Nanofibers (Nylon-6/Ch)}

Nylon-6/chitosan nanofibers were electrospun using nanospider technology. The main advantage of utilizing the Nanospider technology is to synthesis composite nanofibers by blending higher weight percentage chitosan $(8 \%)$ which is difficult to spin with the conventional electrospinning process. The electrospinning was accomplished with the following conditions; active electrode to collecting electrode distance is $14 \mathrm{~cm}$ at a driving voltage of $75 \mathrm{kV}$, active electrode speed is $2.2 \mathrm{rpm}$ and humidity of $37 \%$. The electrospun nanofiber was collected on aluminum sheet and was dried in hood at room temperature till constant weight.

\section{Surface Modification of Electrospun Nylon-6/Chitosan Nano- fibers (nylon-6/HTCC)}

Electrospun nylon-6/chitosan nanofibers mat was treated with excess GTMAC in water with stirring for $24 \mathrm{~h}$ and then the mat was washed with excess water and finally dried in hood at room temp. 


\section{Bacterial Cultures}

Bacterial culture of the Gram-negative bacteria Pseudomonas cichorii and Dickeya dadantii (Erwinia chrysanthemi) were provided from the culture collection of College of Science, Botany and Microbiology Department, King Saudi University, Riyadh, KSA. Enrichment of the culture was carried out according to the method described by [26]. The microorganisms were maintained at $40 \mathrm{C}$ on nutrient agar slants

\section{Antibacterial Activity}

The antibacterial activity assay of nylon-6/HTCC against Pseudomonas cichorii and Dickeya dadantii (Erwinia chrysanthemi) was performed by agar disc diffusion method [27]. Muller Hinton agar medium was seeded with $100 \mu$ of inoculum $\left(1 \times 10^{8} \mathrm{CFU} / \mathrm{ml}\right)$. The impregnated discs $(5 \mathrm{~mm})$ containing nylon-6/HTCC were placed on the agar medium seeded with tested microorganisms. Standard plates with nylon-6/Ch were assessed in parallel as negative control. The plates were then incubated at $37^{\circ} \mathrm{C}$ for $24 \mathrm{hr}$ to allow maximum growth of the microorganisms [28]. The antibacterial activity of the test samples was determined by measuring the diameter of zone of inhibition expressed in millimeter. The assay was repeated twice and the mean of the three experiments was recorded.

\section{Total Protein Determination}

Total protein concentration of Pseudomonas cichorii and Dickeya dadantii (Erwinia chrysanthemi) of the crude homogenate was determined by Coomassie brilliant blue G-250 using bovine serum albumin as standard according to the method of [29].

\section{Protein Separation by SDS-polyacrylamide Gel Electrophoresis}

Samples of 50 ug of Pseudomonas cichorii and Dickeya dadantii (Erwinia chrysanthemi) of crude protein preparation were separated by electrophoresis in $12 \%$ sodium dodecyl sulphate polyacrylamide gels (SDS-PAGE) according to [30] at 150 volts for $90 \mathrm{~min}$. Separated proteins are visualized by Coomassie Brilliant Blue R-250 staining.

\section{Scanning Electron Microscopy (SEM)}

The bacterial cells were prepared according to the initial fixation and dehydration steps previously described [31]. The cells were fixed at $24^{\circ} \mathrm{C}$ for 60 min with $2.5 \%$ glutaraldehyde in $0.1 \mathrm{M}$ sodium cacodylate buffer $(20.15 \mathrm{~g}$ sodium cacodylate trihydrate, $0.1 \mathrm{~mL}$ $\mathrm{HCl}$ in $250 \mathrm{ml}$ distilled water, $\mathrm{pH}=7.4$ ) and then dried on a critical point dryer (HCP2; Hitachi Company, Japan). The dried cell samples were coated with gold, and examined using a scanning electron microscope (S-4100, Hitachi, Japan).

\section{Results and Discussions}

In this study, we successfully obtain electrospun nylon-6/chitosan nanofibers with chitosan concentration $8 \%$ (w/w) of nylon-6 using Nanospider technology as a needless electrospinning technique in which we used up to $75 \mathrm{kV}$ of electrostatic force. The main idea to increasing the chitosan concentration is to use its functional amino group as a carrier for antimicrobial agents. The antimicrobial agent was introduced via surface modification of the electrospun nylon-6/ Ch nanofibers by treatment in aqueous solution of GTMAC at room temperature. The surface modification was confirmed by different method including FT-IR spectroscopy, XRD, TGA as well as FESEM.

\section{Scanning Electron Microscopy}

[Fig-1] shows the FE-SEM images of electrospun nylon-6/chitosan nanofibers before and after surface modification (nylon-6/Ch \& nylon-6/HTCC), respectively. The images showed nanofibers with a smooth surface and uniform diameters along their lengths. As shown in [Fig-1] there is a very clear arrangement of ultrafine meshlike nanofibers strongly bound with the main fibers were observed. These ultrafine nanofiber structures resulted in a large surface area -to-volume ratio. The size of the ultrafine nanofibers is one order less than those of main fibers. The diameter of the nylon-6 nanofibers were observed to be in the range of 44-114 nm, whereas the mesh-like nanofibers structure consisted of regularly distributed very fine nanofibers with diameters of about 10-14 nm. It is believed that the formation of large surface area to volume ratio nanofibers was due to the strong applied voltage that was created between the electrodes.

Also, the fibers had cylindrical morphology and no fiber bundles, indicating that the distance between the active electrode and collecting electrode $14 \mathrm{~cm}$ was adequate for proper evaporation of the solvent.

\section{XRD}

The crystalline structures of as electrospun nylon-6/Ch and nylon-6/ HTCC nanofibers were characterized by XRD, and the result was compared with that acquired from the pristine. The XRD patterns of the electrospun nylon- $6 / C h$ nanofibers before and after surface modification are shown in [Fig-2]. The diffraction pattern of nylon-6/ Ch nanofibers exhibited a narrow peak appeared at $2 q=21^{\circ}$. On the other hand, too feeble peak at $2 q=42^{\circ}$ corresponding to the characteristic of the $g$ phase was also appeared [32]. This result clearly confirms the surface treatment efficiently occurred via immobilization of quaternary ammonium salt group onto the electrospun nylon-6/HTCC nanofibers.

\section{FT-IR Spectra}

The FTIR of the electrospun nanofibers as shown in [Fig-3] showed a resonance band at $1168 \mathrm{~cm}^{-1}$ characteristic of its saccharide structure (unsymmetrical stretching of $\mathrm{C}-\mathrm{O}-\mathrm{C}$ bridges. The bands at $1645 \mathrm{~cm}^{-1}$ is assigned to $\mathrm{C}=0$ stretching of the secondary amide band (amide I) and the $-\mathrm{NH}_{2}$ bending of the primary amino groups as well as the stretching vibrations $\mathrm{C}=0$ of polyamide. Peaks at 1120 and $1074 \mathrm{~cm}^{-1}$ were due to the skeletal vibrations involving the $\mathrm{C}=0$ stretching. The absorption band in the $2856 \mathrm{~cm}^{-1}$ region is characteristic of the stretching vibrations $-\mathrm{CH}_{2}$ - in polyamide backbone. The FTIR spectrum also shows an evidence for introduction of the quaternary ammonium salt group onto chitosan backbone; a new peak occurred at $1462 \mathrm{~cm}^{-1}$ confirms the $\mathrm{C}-\mathrm{H}$ bending of trimethylammonium group. The peak at $3298 \mathrm{~cm}^{-1}$ is assigned to the hydroxyl group stretching. It should be also noted that the $\mathrm{N}-\mathrm{H}$ bending at $1541 \mathrm{~cm}^{-1}$ is assigned to the stretching of the secondary amine due to the change of the primary amine to the secondary amine. According to the FTIR spectrum, the epoxide group of GTMAC has reacted with the $\mathrm{NH}_{2}$ groups rather than the $\mathrm{OH}$ groups of chitosan. This confirmed occurrence of the $\mathrm{N}$-alkylation reaction in chitosan.

\section{Thermogravimetric Analysis (TGA)}

The TGA thermogram of electrospun nanofibers before and after modification (nylon-6/Ch \& nylon-6/HTCC) is shown in [Fig-4]. The thermogram of nylon- $6 / C h$ shows a weight loss of $1.1 \%$ in the range 
starting from 25 to $100^{\circ} \mathrm{C}$ due to the evaporation of the residual absorbed solvents, followed by slow weight loss of $7.6 \%$ in the range starting from 100 to $335^{\circ} \mathrm{C}$ due to the decomposition of polymer with low molecular weight chitosan, dehydration of the saccharide rings, depolymerization and decomposition of the acetylated and deacetylated units of the chitosan. In addition, a maximum weight loss had been observed at the temperature range of 335$500^{\circ} \mathrm{C}$ which may be due to the degradation nylon-6. On the other hand, the thermogram of nylon-6/HTCC shows similar results to that of nylon-6/Ch in addition to the slow weight loss of $4.6 \%$ in the range starting from 100 to $223^{\circ} \mathrm{C}$ due to the degradation of the immobilized active group.
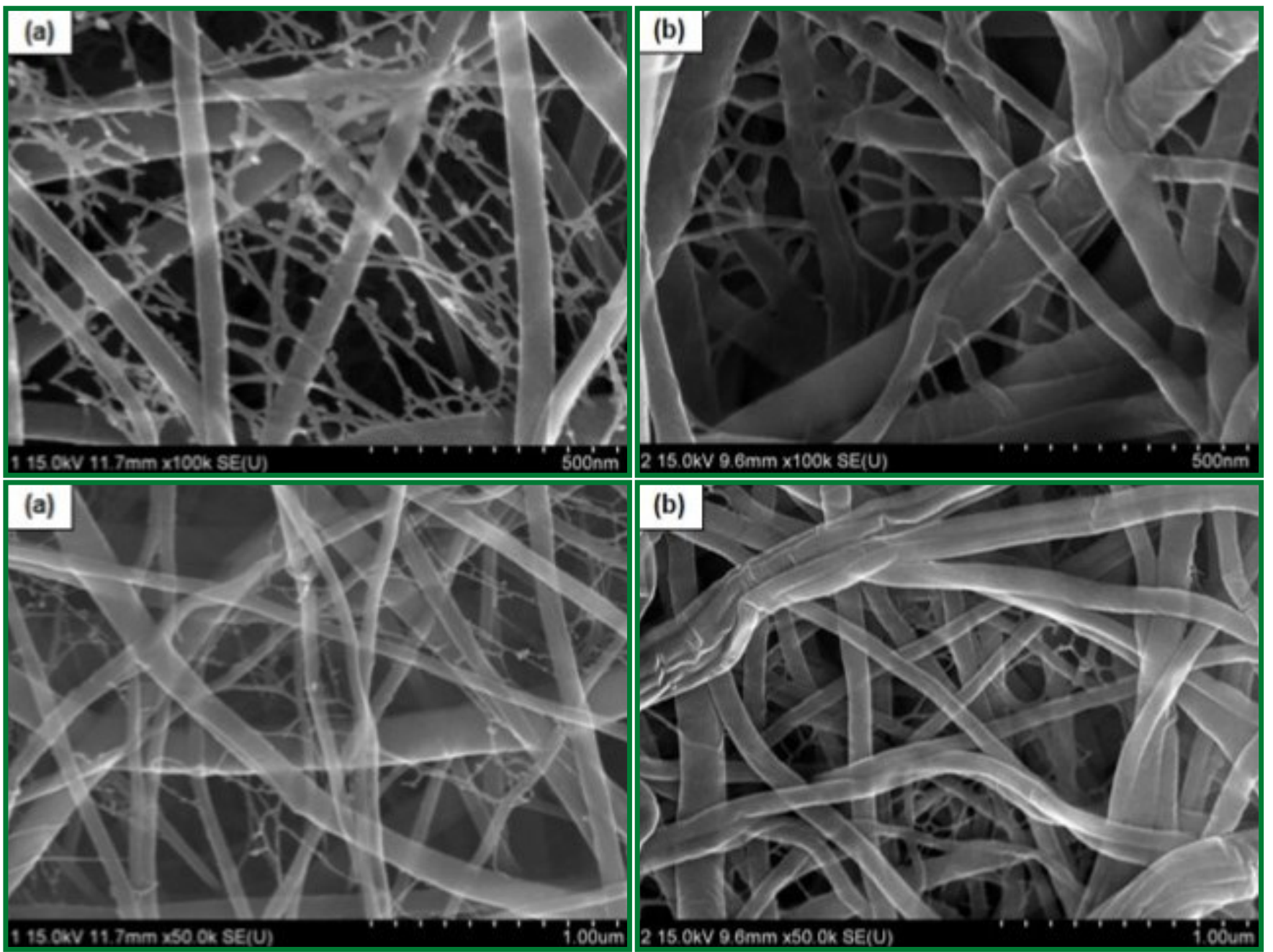

Fig. 1- FE-SEM images of electrospun nylon-6/Ch nanofibers before and after surface modification: (a) electrospun nylon-6/Ch mat; (b) electrospun nylon-6/HTCC

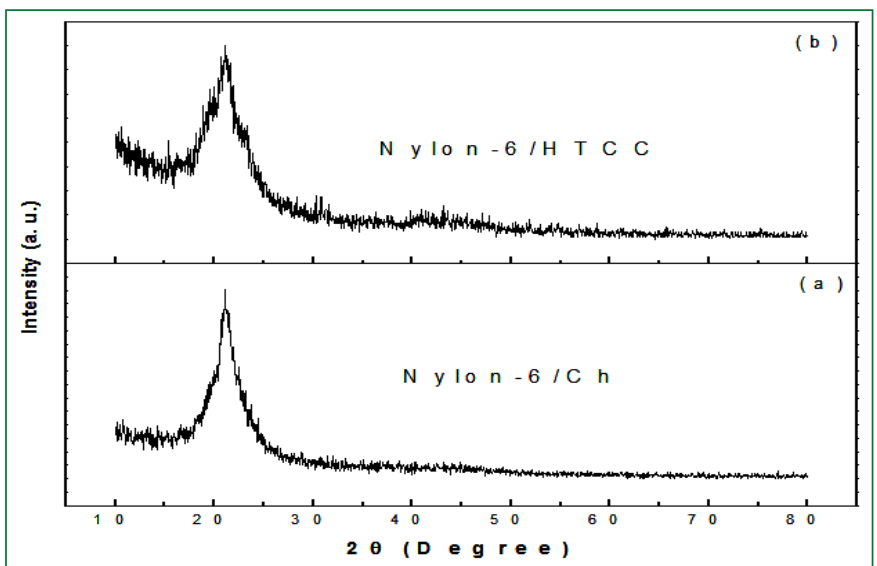

Fig. 2- XRD patterns of electrospun nylon-6/Ch nanofibers before and after surface modification; (a) electrospun nylon-6/Ch mat; (b) electrospun nylon-6/HTCC.

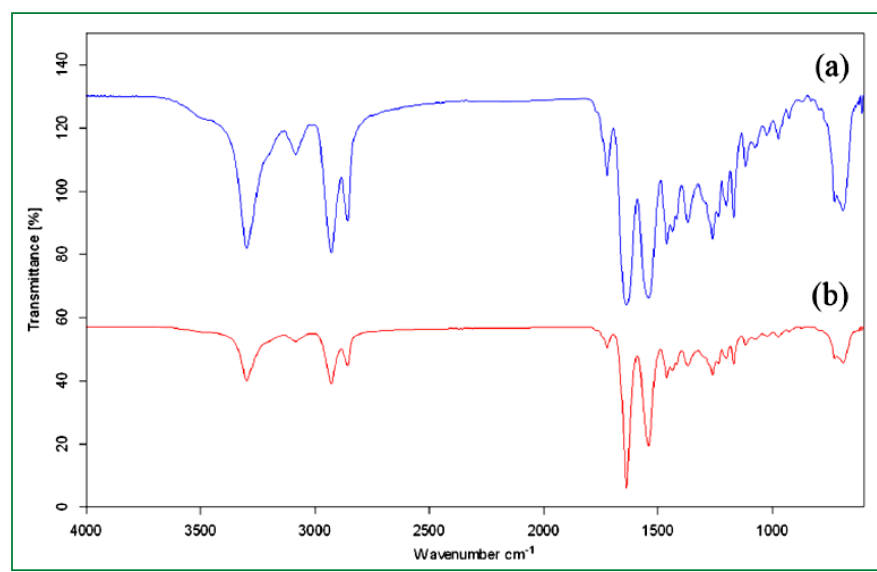

Fig. 3- FT-IR spectra of electrospun nylon-6/Ch nanofibers before and after surface modification; (a) Nylon-6/Ch and (b) Nylon-6/ HTCC. 


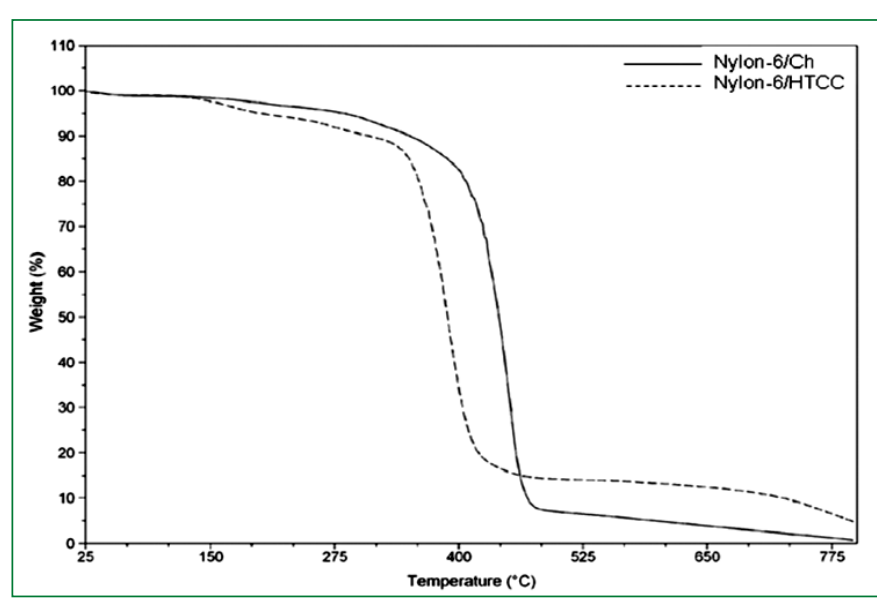

Fig. 4- TGA thermogram of electrospun nylon-6/Ch nanofibers before and after surface modification; nylon-6/Ch and nylon- 6/ HTCC, respectively. The heating speed was $10^{\circ} \mathrm{C} / \mathrm{min}$.

Moreover, the mat leaves a residue of $7.0-14.2 \%$ at $500^{\circ} \mathrm{C}$, whereas the significant weight loss at 422 and $366^{\circ} \mathrm{C}$ indicates the onset ( $T_{\text {on }}$ ) of electrospun nylon-6/Ch and nylon-6/HTCC, respectively.

[Table-1] summarizes the TGA results of nylon-6/Ch and nylon-6/ HTCC electrospun nanofibers. The results demonstrated the confirmation of the surface modification of amino group of chitosan with biological active group which leads to the loss of thermal stability of nylon-6/HTCC compared to the original nylon-6/Ch.

Table 1- Proximate analysis (wt\%) of electrospun nanofibers based on thermogravimetric analysis (TGA).

\begin{tabular}{|c|c|c|c|c|c|c|}
\hline \multirow{3}{*}{ Sample code } & \multicolumn{4}{|c|}{$\begin{array}{l}\text { Distribution of volatile ranges } \\
\text { (Temperature range) }\left({ }^{\circ} \mathrm{C}\right)\end{array}$} & \multirow{3}{*}{$\begin{array}{r}\text { Residue } \\
\text { n at } 500^{\circ} \mathrm{C}\end{array}$} & \multirow{3}{*}{$\begin{array}{l}50 \% \\
\text { Loss } \\
\text { at }\left({ }^{\circ} \mathrm{C}\right)\end{array}$} \\
\hline & evaporation & $\begin{array}{l}\text { Active grou } \\
\text { degradatior }\end{array}$ & $\begin{array}{r}\text { Chitosan } \\
\text { degradatic }\end{array}$ & $\begin{array}{c}\text { Nylon } \\
\text { degradation }\end{array}$ & & \\
\hline & $\begin{array}{l}\text { Zone I } \\
30-100\end{array}$ & $\begin{array}{c}\text { Zone II } \\
100-223\end{array}$ & $\begin{array}{l}\text { Zone III } \\
223-328\end{array}$ & $\begin{array}{l}\text { Zone IV } \\
328-500\end{array}$ & & \\
\hline Nylon-6/Ch & 1.1 & & & 84.3 & 7 & 440 \\
\hline Nylon-6/HTCC & 0.7 & 4.7 & 5.5 & 74.6 & 14.2 & 388 \\
\hline
\end{tabular}

\section{Antibacterial Assessment}

The biological assessments explored by the disc diffusion method revealed that nylon-6/HTCC mat exhibited potential antibacterial activity against $P$ seudomonas cichorii and Dickeya dadantii (Erwinia chrysanthemi). The reduction of the colony formation was observed after $12 \mathrm{hrs}$. post treatment. The zone diameter was 20 and $22 \mathrm{~mm}$, respectively [Fig-5]. The control sample (nylon-6/Ch) exhibits no inhibition activity.

In general observation, Pseudomonas cichorii and Dickeya dadantii (Erwinia chrysanthemi) examined using SEM were totally deformed and exhibited severe destruction [Fig-6]. In case of Pseudomonas cichorii, the surfaces of the bacterial cells were totally damaged. It was found also that the intact cells had a smooth surface, while most of the exposed bacterial cells exhibited severe destruction. Furthermore, the damage to the surface structure of Pseudomonas cichorii cells may, therefore, be the main reason for exposure by nylon-6/HTCC.

In fact, it is well known that nylon-6/HTCC exposed cells remained unlysed in suspension, in some cases of the cells. It was found that intact cells had a smooth surface with overall intact morphology. For Pseudomonas cichorii, it was observed that many cells were en- larged, elongated and highly irregular. However, it was observed a pronounced deformation and visible shrinkage and this was mainly due to the binding of antimicrobial agents to the certain receptors of the bacterial membrane that lead to the disruption of the cytoplasmic membrane and thus inhibits the growth.

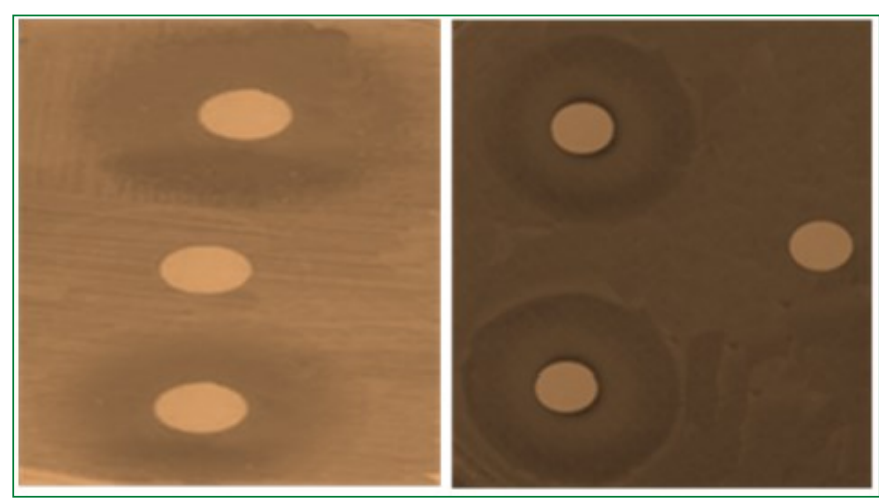

Fig. 5- Inhibition Zones of nylon-6/HTCC mat against Dickeya dadantii (Erwinia chrysanthemi) (right) and Pseudomonas cichorii (left) by disc diffusion method on nutrient agar at $37^{\circ} \mathrm{C}$.

The lethal action of polycationic biocides can be interpreted and identified as modes of action: (1) adsorption onto the bacterial cell surface; (2) diffusion through the cell wall; (3) binding to the cytoplasmic membrane; (4) disruption of the cytoplasmic membrane; (5) release of the cytoplasmic constituents such as $\mathrm{K}^{+}$ions, DNA, RNA; and (6) death of the cell $[33,25]$.

Dickeya dadantii (Erwinia chrysanthemi) cells become rough and swollen, the structure of the cell wall surface layer was wrinkled, and round pores were partially deformed, indicating that the cytoplasmic structures were flushed out of the cells but they were unlysed. The result suggests that the bacterial cell surfaces are negatively charged. Therefore, adsorption onto the negatively charged cell surface (process 1) is expected to be enhanced with the increasing charge density of the cationic biocides. Therefore, it is reasonable to assume that process 1 is much more enhanced for polymers than for model compounds [34]. A similar situation can also be expected in process 3 because there are many negatively charged species present in the cytoplasmic membrane, such as acidic phospholipids and some membrane proteins [35-38]. The disruption of the membrane (process 4 ) is a result of the interaction of the bound polymers with the membrane disruption and, therefore, is expected to be facilitated with increasing amounts of the bound polymers. Pseudomonas cichorii and Dickeya dadantii (Erwinia chrysanthemi).

The separation of proteins extracted from control (lane 1) and treated (lane 2) [Fig-7] Pseudomonas cichorii indicated that there is a minor change in the protein profile after treatment with nylon-6/ HTCC, while a very clear change in the profile was appeared in Dickeya dadantii (Erwinia chrysanthemi) as a high molecular weight protein band was existed in the untreated bacteria and disappeared after treatment.

New low molecular weight band is appeared after treatment. This may indicate that some gene expressing high molecular weight protein is destroyed. The change in the gene may occur by developing a mutation in its sequence giving a new stop codon causing immature termination of protein synthesis or by a breakdown in the DNA backbone inside this gene. The second hypothesis can be strengthened by DNA fragmentation experiment. 

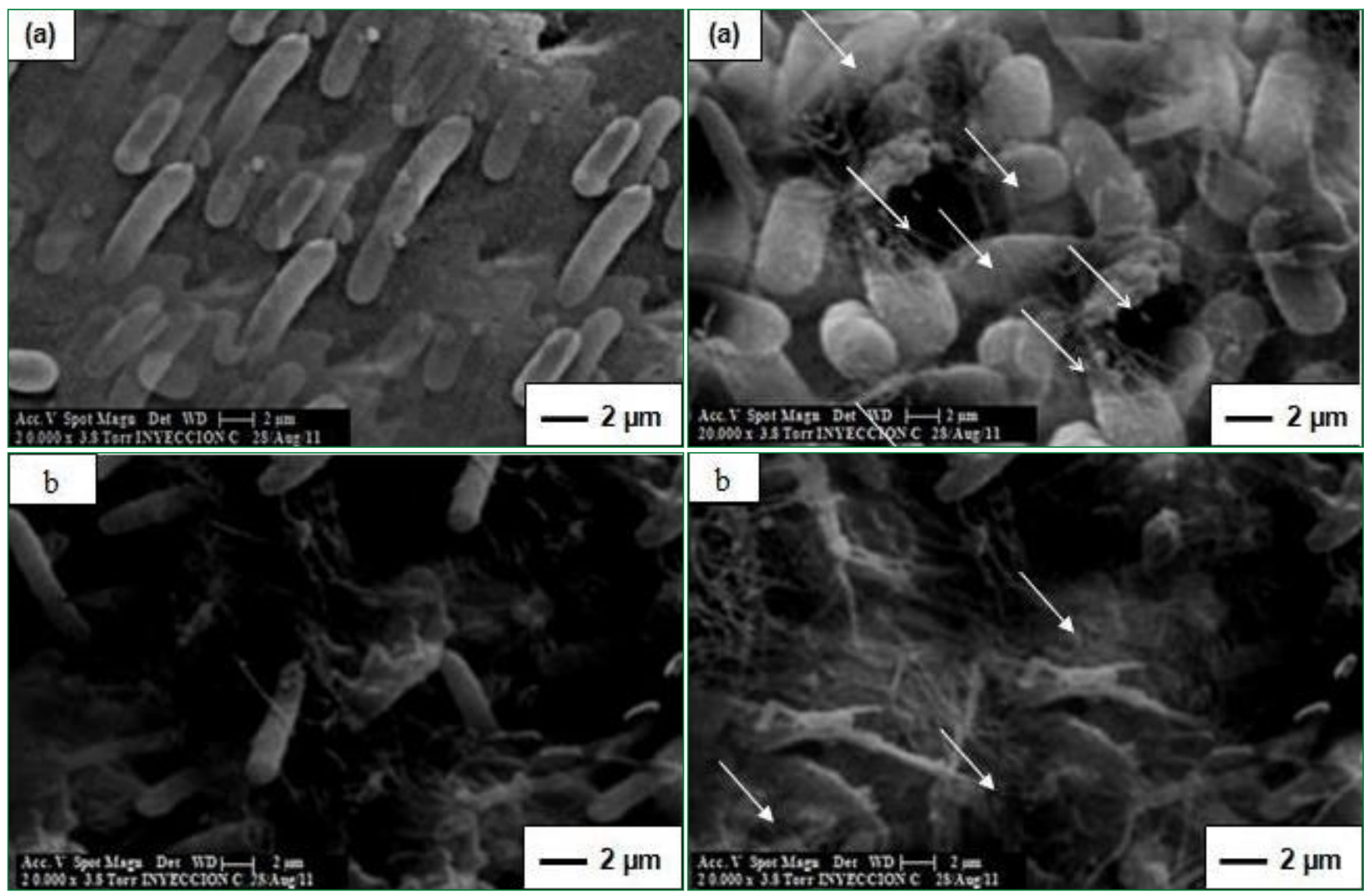

Fig. 6- Scanning Electron Micrograph (SEM) demonstrating effect of nylon-6/HTCC mat on (a) Dickeya dadantii (Erwinia chrysanthemi); (b) Pseudomonas cichorii.

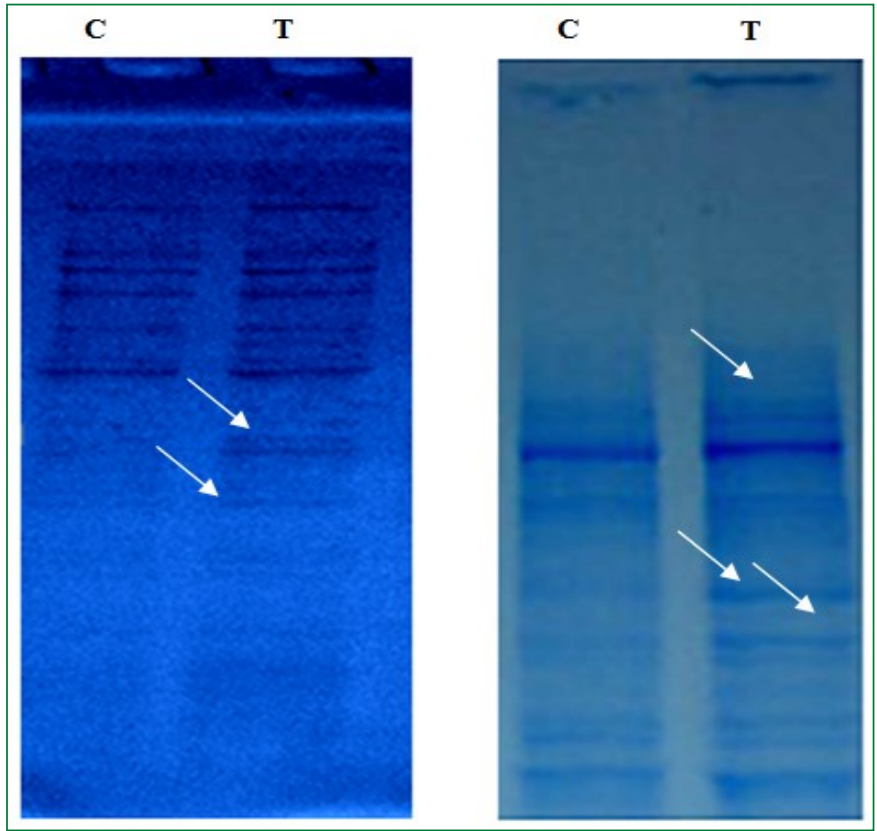

Fig. 7- Effect of nylon-6/HTCC mat on the protein of Dickeya dadantii (Erwinia chrysanthemi) (left) and Pseudomonas cichorii (right); (C) Control \& (T) Treatment cells

The cell surface topology of Pseudomonas cichorii was specified by a dense coat of characteristic protuberant structures. Taken the previous results into the accounts, antimicrobial agent could be described as polymeric biocides. They are a class of polymers with antimicrobial activity, or the ability to inhibit the growth of microorganisms such as bacteria, fungi or any other micro-organisms. Nylon-6/HTCC have been engineered to mimic antimicrobial peptides which are used by the immune systems of living things to kill bacteria [39]. They are active against microorganisms by interaction with the cellular membrane and aimed to kill microorganisms [40].

In fact, polymers containing antibiotics are one of our most important weapons in fighting bacterial infections and have greatly benefited the health-related quality of human life since their introduction. However, over the past few decades these health benefits are under threat as many commonly used antibiotics have become less and less effective against certain illnesses not only because many of them produce toxic reactions but also due to emergence of drug resistant bacteria. It is essential to investigate newer polymers containing drug with lesser resistance. Systematic studies among various pharmacological compounds have revealed that any drug may have the possibility of possessing diverse functions and thus may have useful activity incompletely different spheres of medicine. Therefore, the results of the present investigation is successful in identifying new antibacterial activity of polymer and ascertains its value in the development of new anti-microbial materials.

Finally, we present an appropriated chemical reaction for the possible surface modification which is illustrated in the [Scheme-1]. As shown in the scheme, the quaternary ammonium salt group (-NH$\left.\mathrm{CH}_{2}-\mathrm{CH}(\mathrm{OH})-\mathrm{N}^{+}\left(\mathrm{CH}_{3}\right)_{3} \mathrm{Cl}\right)$ was introduced onto chitosan backbone during surface modification process. This proposed mechanism is in good agreement with the XRD and FTIR data as shown in [Fig-2] and [Fig-3]. 


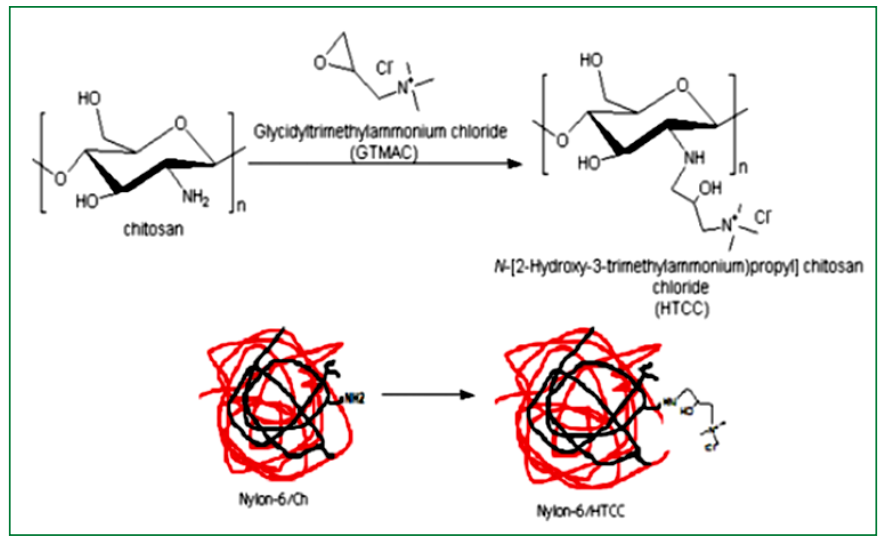

Scheme 1- Surface modification of nylon-6/Ch with GTMAC

\section{Conclusion}

Electrospun nylon-6/Ch nanofibers prepared using Nanospider technology as a carrier for antimicrobial drugs. The introduction of glycidyltrimethylammonium chloride (GTMAC), as antimicrobial drug was confirmed by FTIR spectra, XRD, thermal analysis and FE -SEM. The electrospun nanofibers exhibited high inhibitory effects against the microbes. The results were clearly indicated that the antimicrobial activity of the electrospun nanofibers varies with the species of the organisms used. Thus, the study ascertains the value of the use of electrospun nanofibers which could be of considerable interest in the development of new anti-microbial materials for biomedical applications. SEM image of the affected microbes was totally deformed and exhibited severe destruction. Abnormal cell division was observed at high frequencies among cells that tried to divide in the presence of the polymer. Many cells were enlarged, elongated, empty ghosts, or fragmented, consistent with the extremely low viability modified technique of electrospinning. Therefore this finding spots the light of the nanotechnology applications in the fields of medical and life sciences. Moreover, this adverse affects of nylon-6/Ch could be also used in general toxicology of nanoscale materials.

\section{Acknowledgements}

The authors extend their appreciation to the Deanship of Scientific Research at King Saud University, for funding the work through the research group project No RGP-VPP-010.

Conflicts of Interest: None declared.

\section{References}

[1] De Britto A.J., Gracelin D. and Sebastian S.R. (2011) Journal of Biopesticides, 4(1), 57-60.

[2] Mandavia M.K., Gajera H.P., Andharia J.H., Khandar R.R. and Parameshwaram M. (1999) Indian Phytopathology, 50, 548551.

[3] Bradbury J.F. (1986) Guide to Plant Pathogenic Bacteria, CAB International, Wallingford UK, 61-79.

[4] Pérombelon M.C.M., Kelman A. (1987) Plant Disease, 71, 283285.

[5] Pérombelon M.C.M., Lumb V.M., Hyman L.J. (1987) EPPO Bulletin, 17, 25-36.

[6] Smith I.M., Dunez J., Phillips D.H., Lelliott R.A., Archer S.A. (1988) European Handbook of Plant Diseases, Oxford: Blackwell Scientific Publications, 583.
[7] Mirik M., Aysan Y. and Sahin F. (2011) International Journal of Agriculture \& Biology, 13, 203-209.

[8] El-Shafei M.A., Fouda M.M., Knittel D. and Schollmeyer E. (2008) J. Appl. Polym. Sci., 110, 1289-1296.

[9] Fouda M.M., El Shafei A., Sharaf S., Hebeish A. (2009) Carbohydrate Polymer, 77(3), 651-655.

[10]Hebeish A., Abdel-Mohdy A.F., Fouda M.M., Elsaid Z., Essam S., Tammamg H., Drees A.E. (2011) Carbohydrate Polymer, 86, 1684-1691.

[11]El-Newehy M.H., Al-Deyab S., Kenawy E.R., Abdel-Megeed A. (2011) Journal of Nanomaterials, 9, doi:101155/2011/626589.

[12]Fahmy H.M. and Fouda M.M. (2008) Carbohydrate Polymer, 73, 606-611.

[13]Abdel-Halim E.S. and Al-Deyab S.S. (2011) Carbohydrate Polymer, 86, 1615-1622.

[14]Hebeish A., El-Rafie M.H., Abdel-Mohdy F.A., Abdel-Halim E.S., Emam H.E. (2010) Carbohydrate Polymer, 82(3), 933941.

[15]Abdel-Halim E.S., Abdel-Mohdy F.A., Al-Deyab S.S., ElNewehy M.H. (2010) Carbohydrate Polymer, 82, 202-208.

[16]Nirmala R., Kang H.S., El-Newehy M.H., Navamathavan R., Park H.M., Kim H., Human Y. (2011) J. Nanosci. Nanotechnol., 11, 4749-4756.

[17]Ma Y., Zhou T. and Zhao C. (2008) Carbohydrate Research, 343, 230-337.

[18]Stephens J.S., Chase D.B., Rabolt J.F. (2004) Macromolecules, 37(3), 877-881.

[19]Nirmala R., Navamathavan R., Kang H.S., El-Newehy M.H., Kim H.Y. (2011) Biointerfaces, 83(1), 173-178.

[20]Zhang D., Karki A.B., Rutman D., Young D.P., Wang A., Cocke D., Ho H.T., Guo Z. (2009) Polymer, 50(17), 4189-4198.

[21]Yang R., He J., Xu L., Yu J. (2009) Polymer, 50(24), 58465850.

[22]Song J.H., Kim H.E., Kim H.W. (2007) Journal of Biomedical Materials Research, Part B: Applied Biomaterials, 83(1), 248257.

[23]Binulal N.S., Deepthy M., Selvamurugan N., Shalumon K.T., Suja S., and Ullas M. (2010) Tissue Eng., 16, 393-404.

[24]Xu C.Y., Inai R., Kotaki M. and Ramakrishna S. (2004) Biomaterials, 25, 877-886.

[25]Dizman B., Elasri M.O., Mathias L.J. (2004) Journal of Applied Polymer Science, 94(2), 635-642.

[26]Abdel-Megeed A. (2011) Pak. J. Bot., 43, 29-39.

[27]Hayat M.A. (1981) Principles and Techniques of Electron Microscopy, Edward Arnold Ltd., London, 522-529.

[28]Bauer A.W., Kibry W.M.M., Sherris J.C., Turck M. (1966) Am. J. Clin. Pathol., 45, 493-496.

[29]Bradford M.M. (1976) Analytical Biochemistry, 72(1), 248-254.

[30]Laemmli U.K. (1970) Nature,15, 680-685.

[31]Tung J., Gupta R.K., Simon G.P., Edward G.H., Bhattacharya S.N. (2005) Polymer, 46, 10405-10418.

[32]Abel T., Cohen J.I., Engel R., Filshtinskaya M., Melkonian A., and Melkonian K. (2002) Carbohydrate Research, 337, 24952499. 
[33]Katchalsky A. (1964) Biophys J., 4(9), 132-136.

[34]Anguiz R. (1989) Plant Dis., 73, 199-201.

[35]Kenawy E.R., Abdel-Hay F.I., El-Newehy M.H., Wnek G.E. (2007) Mater. Sci. Eng., 459, 390-396.

[36]Kenawy E.R., Abdel-Hay F.I., El-Newehy M.H., Wnek G.E. (2009) Mater. Chem. Phys., 113, 296-302.

[37]Kenawy E., Abdel-Hay F.I., El-Shanshoury A.E.R., El-Newehy M.H. (2002) J. Polym. Sci., Part A Polymer Chemi., 40, 23842393.

[38]Ghazzali M.M., El-Faham A., Abdel-Megeed A. Al-Farhan K. (2012) Journal of Molecular Structure, 1013, 163-167.

[39]Emily H., Azzopardi K., Taing H., Graichen F., Jeffery J., Mayadunne R., Wickramaratna M., O'Shea M., Nijagal B., Watkinson R., O'Leary S., Finnin B., Tait R. and Robins-Browne R. (2010) Journal of Antimicrobial Chemotherapy, 65(5), 974980.

[40]Laskar H., Nurdin N., Helary G., Sauvet G. (1993) J. Appl. Polym. Sci., 50, 651-662. 